\title{
Editorial
}

\section{Colony Collapse Disorder May Affect Complementary and Alternative Medicine}

\author{
Edwin L. Cooper \\ Laboratory of Comparative Neuroimmunology, Department of Neurobiology, David Geffen School of \\ Medicine at UCLA, Box 951763, 63-230 CHS, Los Angeles California 90095-1763, USA
}

Very recently some surprising and puzzling news appeared in the media: television and newspapers, reporting a phenomenon perhaps akin to a population crash. It sounded like a pandemic in that it occurs over a large area of the world - not an epidemic, an outbreak of a disease that spreads rapidly through a community. The news caught my immediate attention since the affected population particularly concerns my initiative to advance bioprospecting (1) and more specifically biotherapy (I lectured at the VII Biotherapy Congress, Seoul Korea, June 20-25, 2007). From the inception of $e C A M$ there has been a conscious effort to capture or focus on the beneficial effects of natural products, especially those derived from marine and terrestrial animals. The jolting news concerns honeybees and a phenomenon referred to as Colony Collapse Disorder (CCD), a disorder in which disturbing numbers of bees are disappearing from their colonies. This is of great interest for the basic science and application of products from honeybees and the broader context of agriculture and CAM.

Of all the printed media, the most appropriate coverage was featured in The Economist, April 28, 2007, page 92. One article was entitled: 'Dying bees buzz off' and the other: 'Medical use of honey: Sticky solution'. Actually neither of these articles mention propolis, the product of honeybee activity that is the focus of some of $e C A M$ 's most popular articles (2-9). According to the first article, $\mathrm{CCD}$, as the phenomenon has become known, was first

For reports and all correspondence: Edwin L. Cooper, $P h D, S c D$, Laboratory of Comparative Neuroimmunology, Department of Neurobiology, David Geffen School of Medicine at UCLA, Box 951763, 63-230 CHS, Los Angeles California 90095-1763, USA.

Tel: (310) 825-9567; Fax: (310) 825-2224;

E-mail: ecam@mednet.ucla.edu reported in America in mid-November 2006. It spread rapidly with beekeepers reporting heavy losses of between 30 and $90 \%$ of bees. Some 24 American states have now reported cases of CCD. It has also been seen in Greece, Italy, Poland, Portugal and Spain. Because the living bees that scientists were able to analyze carried almost every virus and parasite known to infect honeybees, researchers are working on the idea that the insects' immune systems have failed. Reduction in the body's ability to fight diseases allows infection by a host of pathogens. But exactly why this should happen is unclear. It could be that one disease, perhaps a new type of 'lurgy', invites the others to infect the bee, or that a pesticide performs this role. The researchers interviewed beekeepers to determine if some practices were more likely to lead to CCD. At first they found that beekeepers who frequently moved their hives seemed to have bees that were more likely to be affected. Perhaps this constant moving is stressful for the bees and so depresses their immune systems.

In the companion article the thrust is more towards what the bees' product, honey, can offer. 'Hospitals do more than house sick patients while they are treated. They also provide convenient havens for dangerous bacteria. Cramming infirm people into one place creates the ideal breeding ground for disease. Add a sprinkling of antibiotics and drug-resistant strains emerge - the superbugs that are endemic in many places. One doctor, however, thinks he has rediscovered an old weapon that could be useful in the fight against these nasties. It is honey. Honey was commonly used in medicine before antibiotics became widespread. It is still used in the Antipodes; an Australian company makes a product called Medihoney for medicinal use. This formulation is a certified medicine in Europe, but has not

This is an Open Access article distributed under the terms of the Creative Commons Attribution Non-Commercial License (http://creativecommons.org/ licenses/by-nc/2.0/uk/) which permits unrestricted non-commercial use, distribution, and reproduction in any medium, provided the original work is properly cited. 
been much used there because doctors developed a taste for prescribing conventional antibiotics. Arne Simon of Bonn University Children's Clinic in Germany is now leading an international study to compare honey with existing drugs. The investigation will involve 150 patients in several countries including Britain, Germany and Australia. Dr Simon has already used honey on 150 patients who were not responding to treatment, with some promising results. The patients were often children whose immune systems had been weakened by chemotherapy, which left their wounds from surgery vulnerable to infection. Around a third of them were also given some antibiotics at the same time as having their wounds dressed with honey. One patient, whose wounds had become infected by the potentially fatal strain of Staphylococcus aureus that is resistant to the antibiotic methicillin (MRSA), and who failed to respond to other drugs, was free of this superbug within 48 hours of receiving the honey treatment.' This excerpt has now been expanded (10).

Turning now to $e C A M$, we have targeted papers dealing with propolis. All the investigators agree essentially on the nature of propolis as a product of honeybees and they reveal variable composition depending on the country of origin. Propolis is a hive product containing chiefly beeswax and plant-derived substances such as resin and volatile compounds. Propolis has been used as an antiseptic and wound healer since ancient times and interest for the product has increased recently. Probably few plant species contribute as major resin sources. Green propolis derives mainly from vegetative apices of Baccharis dracunculifolia (alecrim plants). However, wide variation detected in the chemical composition suggests contributions from alternative resin plant sources. Predominant components of the resin of green propolis are cinnamic acids, chiefly compounds bearing prenyl groups. Terpenoid compounds, such as sesqui, di and pentacyclic triterpenoids, have been detected in many, but not all, samples investigated. Propolis research has uncovered potentialities of substances previously isolated from plants and has detected constituents of plant origin that would hardly be known otherwise. Analyses also focus on various assays designed to test the efficacy especially viewing in vitro models. Certain studies merit more attention as they focus on the nervous and immune systems.

Inokuchi et al. (7), confirm that propolis has gained popularity as a food and alternative medicine. Its constituents have been shown to exert pharmacological (anticancer, antimicrobial and anti-inflammatory) effects. They investigated whether Brazilian green propolis exerts neuroprotective effects in the retina in vitro and/or in vivo. Propolis inhibited the neurotoxicity and apoptosis induced in cultured retinal ganglion cells. These findings indicate that Brazilian green propolis has neuroprotective effects against retinal damage both in vitro and in vivo, and that a propolis-induced inhibition of oxidative stress may be partly responsible for these neuroprotective effects.

According to Missima and Sforcin (9), stress is a generic term that summarizes how psychosocial and environmental factors influence physical and mental well-being. The interaction between stress and immunity has been widely investigated, involving the neuroendocrine system and several organs. Assays using natural products in stress models deserve further investigation. Propolis' immunomodulatory action has been mentioned and it has been the subject of scientific investigation. They evaluated if and how propolis activated macrophages in BALB/c mice submitted to immobilization stress, as well as the histopathological analysis of the thymus, bone marrow, spleen and adrenal glands. Stressed mice showed a higher hydrogen peroxide $\left(\mathrm{H}_{2} \mathrm{O}_{2}\right)$ generation by peritoneal macrophages, and propolis treatment potentiated $\mathrm{H}_{2} \mathrm{O}_{2}$ generation and inhibited nitric oxide (NO) production by these cells. Histopathological analysis showed no alterations in the thymus, bone marrow and adrenal glands, but increased germinal centers in the spleen. Propolis treatment counteracted the alterations found in the spleen of stressed mice. New research is being carried out in order to elucidate propolis' immunomodulatory action during stress.

In summary, what does all of this mean? $\mathrm{CCD}$ is real but its cause is unknown despite plausible ideas such as stress that may weaken the honeybee's immune system. Most importantly these citations and media reports about CCD will perhaps have a longer term or later effect on CAM - of course the immediate being possible severe effects on aspects of the agricultural industry. Estimates in the billions of dollars underscores our reliance on bees for honey production and pollination of fruits, vegetables and nuts, especially the multi-billion dollar almond crops (11). Because of this threat to bees are we thinking of ways to mimic the honeybees' ability in pollinating? If the beginning devastation caused by CCD continues will we create a newer synthetic mechanized honeybee capable of pollination that could thus facilitate other biomedical practices associated with Apis that have become so essential to CAM? And apitherapy is wide ranging (12).

To give you an idea of what the world would lose with the disappearance of the bee, I refer to the website of $<$ apimondia.org $>$ in which the hive is called 'the oldest laboratory of the world.' In that site, the myriad aspects of honey, bee bread, propolis, royal jelly, bee venom, bee wax and bee larvae are linked to treatments of all the major pathologies from nutritional problems to arthritis, rheumatism and 23 other areas. Of course, all these treatments do not have an evidence base but imagine how fertile the hive and its products are for evidence-based research! In this time of crisis, I hope that scientists all over the world turn their brilliant minds to the mystery of $\mathrm{CCD}$ and that researchers continue to seek an evidence 
base for the miraculous honey bee. And as you can see by our past issues, $e C A M$ is a bee-friendly publication.

\section{References}

1. Cooper EL. Bioprospecting a CAM frontier. Evid Based Complement Alternat Med 2005;2:1-3.

2. Chen CN, Weng MS, Wu CL, Lin JK. Comparison of radical scavenging activity, cytotoxic effects and apoptosis induction in human melanoma cells by Taiwanese propolis from different sources. Evid Based Complement Alternat Med 2004;1:175-85.

3. Salatino A, Teixeira EW, Negri G, Message D. Origin and chemical variation of Brazilian propolis. Evid Based Complement Alternat Med 2005;2:33-8.

4. Bankova V. Recent trends and important developments in propolis research. Evid Based Complement Alternat Med 2005;2:29-32.

5. Teixeira EW, Negri G, Meira RMSA, Message D, Salatino A. Plant origin of green propolis: bee behavior, plant anatomy and chemistry. Evid Based Complement Alternat Med 2005;2:85-92.

6. Shimazawa M, Chikamatsu S, Morimoto N, Mishima S, Nagai H, Hara H. Neuroprotection by Brazilian green propolis against in vitro and in vivo ischemic neuronal damage. Evid Based Complement Alternat Med 2005;2:201-207.

7. Inokuchi Y, Shimazawa M, Nakajima Y, Suemori S, Mishima S, Hara H. Brazilian green propolis protects against retinal damage in vitro and in vivo. Evid Based Complement Alternat Med 2006:3:71-7.

8. Trusheva B, Popova M, Bankova V, Simova S, Marcucci MC, Miorin PL, et al. Bioactive constituents of Brazilian red propolis. Evid Based Complement Alternat Med 3:249-54.

9. Missima F, Sforcin JM. Green Brazilian propolis action on macrophages and lymphoid organs of chronically stressed mice. Evid Based Complement Alternat Med. Advance Access published on February 17, 2007, doi 10.1093/ecam/nel112.

10. Simon A, Traynor K, Santos K, Blaser G, Bode U, Molan P. To bee or not to bee - is that the question? Evid Based Complement Alternat Med (in press).

11. Stokstad E. The case of the empty hives. Science 2007;316:970-72.

12. Kim KS, Choi US, Lee SD, Kim KH, Chung KH, Chang YC, et al. Effect of bee venom on aromatase expression and activity in leukaemic FLG 29.1 and primary osteoblastic cells. J Ethnopharmacol 2005;99:245-52. 


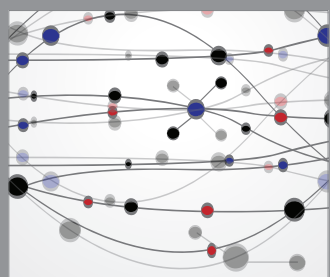

The Scientific World Journal
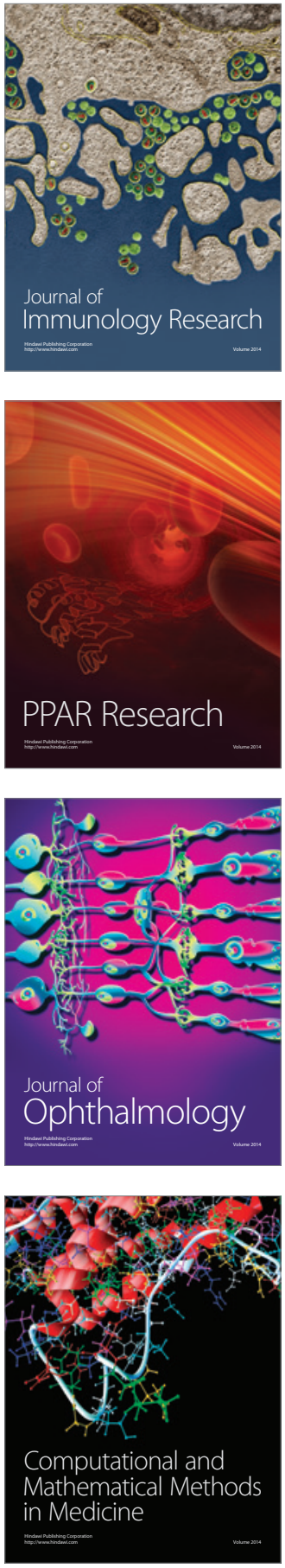

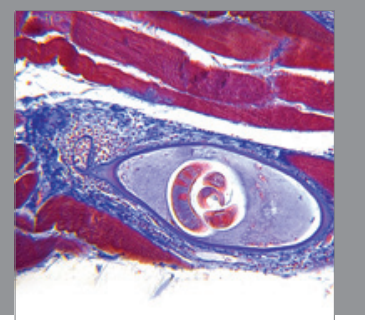

Gastroenterology

Research and Practice
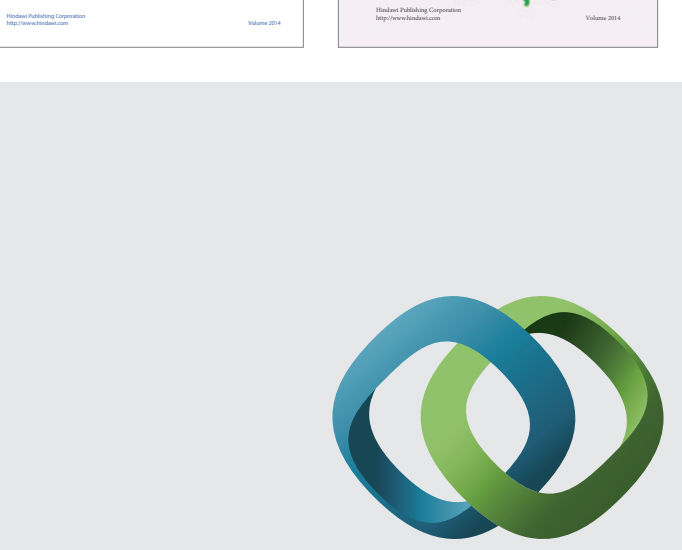

\section{Hindawi}

Submit your manuscripts at

http://www.hindawi.com
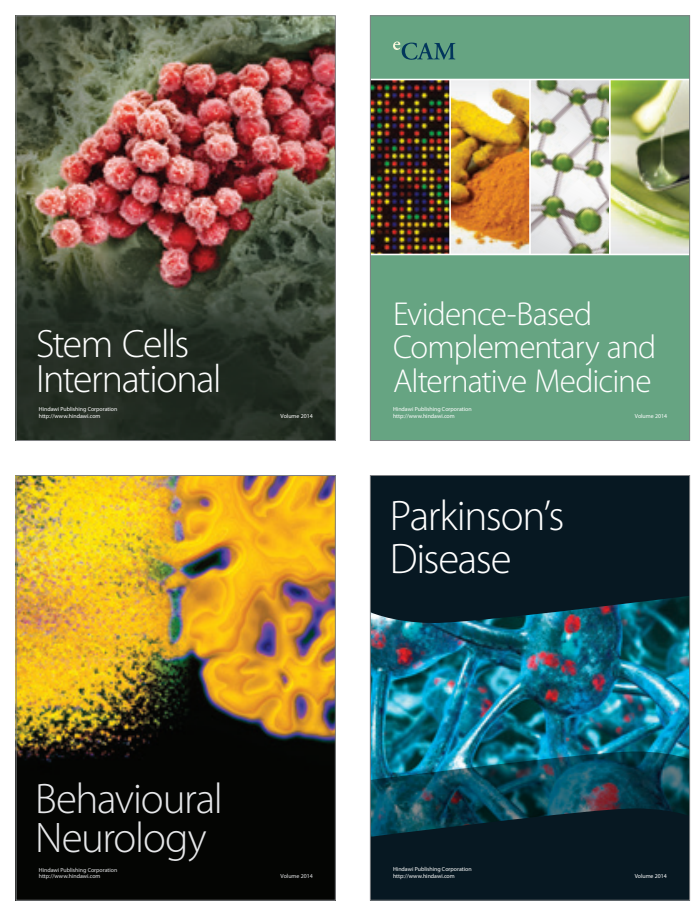

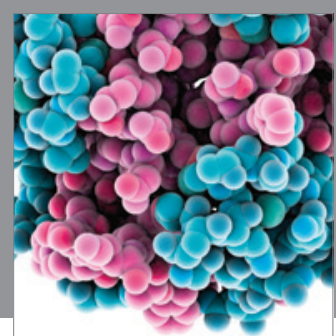

Journal of
Diabetes Research

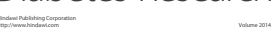

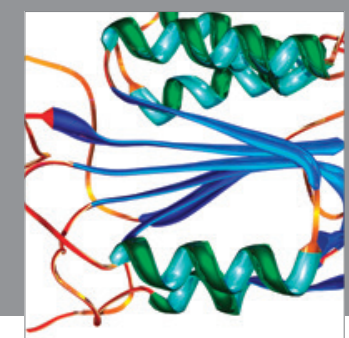

Disease Markers
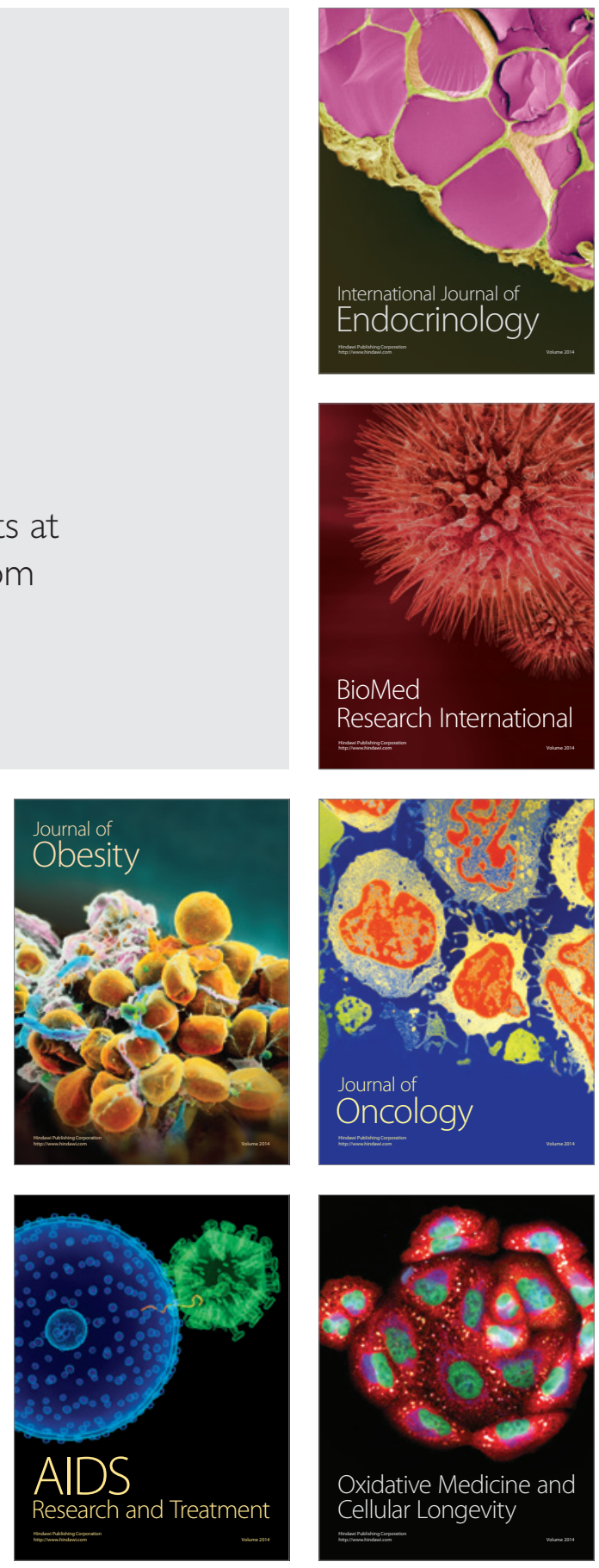